https://www.scilook.eu/index.php/slif/article/view/slif16-028 DOI: 10.30888/2415-7538.2020-16-02-028

\title{
УДК 7.613.4
}

\section{ВЗАИМОСВЯЗЬ ФИЗИЧЕСКОЙ КУЛЬТУРЫ И ОБРАЗА ЖИЗНИ СТУДЕНТОВ}

\section{RELATIONSHIP OF PHYSICAL CULTURE AND LIFESTYLE OF STUDENTS}

Kosyreva I.I. / Косырева И.И.

Senior teacher/ Старший преподаватель Sharipova G.K. / Шарипова Г.К.

Senior teacher/ Старший преподаватель

Rozhko G.T./ Рожко Г.T.

Senior teacher/ Старший преподаватель

Taraz State University named after M.Kh.Dulaty, Kazakhstan, Taraz,60 Tole by street, 080000 Таразский Государственный Университет им. М.Х.Дулати, Казахстан, Тараз, ул Толе би 60

Аннотация. В работе рассматривается влияние занятий физической культурой и спортом на подготовленность, выносливость студентов к учебному процессу в вузе.

Ключевые слова: здоровье, здоровый образ жизни (ЗОЖ), физическое воспитание, физическая культура, студенческая молодежь.

Цель статьи: Выявить отношение студентов вуза к формированию здорового образа жизни.

Целью исследования является выявление отношения студентов ТарГУ им. к формированию здорового образа жизни.

\section{Задачи:}

1.Выявить, что понимают студенты ТарГУ под здоровым образом жизни

2.Установить отношение студенческой молодежи к здоровому образу жизни

3.Выяснить, хотят ли студенты вести здоровый образ жизни

4.Определить, как молодежь пытается вести здоровый образ жизни

5.Определить причины, барьеры, которые мешают вести здоровый образ жизни

Предмет исследования: Влияние социально-психологических факторов на отношение студентов к ведению здорового образа жизни.

Объект исследования:_студенты 1 и 2 курса ТарГУ им.М.Х. Дулати всех специальностей.

Актуальность темы: Здоровый образ жизни в последние годы стал актуальной темой для обсуждения, раньше этот вопрос поднимался лишь при обследовании у врача, а сегодня мы можем услышать и увидеть призывы к здоровому образу жизни практически везде: как на телевидении, так на радио и в газетах.

В данном исследовании мы узнаем отношение студентов к здоровому образу жизни. И попробуем выявить факторы, которые оказывают влияние на образ жизни студентов колледжа. Потому, что ведение нездорового образа жизни наносит непоправимый урон здоровью, который если не проявляется сразу, то обязательно откликнется в дальнейшем.

По этим причинам данное исследование на сегодняшний день является особенно актуальным. 


\section{Гипотезы:}

1. Современная студенческая молодежь под здоровым образом жизни понимает занятие физической культурой и спортом, отказ от вредных привычек, рациональное питание, режим труда и отдыха.

2. В ТарГУ имени М.Х. Дулати для студентов созданы условия для полноценных занятий физической культурой и занятий на курсах спортивного совершенствования по видам спорта. Студенческая молодежь положительно относится к здоровому образу жизни, посещает различные спортивные секции и спортзалы.

3. У студенческой молодежи недостаточно средств для соблюдения режим рационального питания.

4. Вредные привычки мешают вести здоровый образ жизни.

\section{Методы исследования:}

Основным методом исследования в данной работе выбрана форма опроса. Она наиболее удобна при обработке и анализе данных, так же позволяет значительно сократить время сбора информации, чего бы ни произошло при методе беседы или интервьюирования. Наша работа нацелена на доказательство регулярных занятиями физической культурой и спортом студенческой молодежи. Постоянно говорится об этом, выделяется физическая культура как самостоятельный феномен, вырабатывающий устойчивость такого качество как личность. По выражению Н.Н. Визитей - физическая культура является первой базовой культурой, которая формируется в человеке. Физическая культура влияет на состояние организма, психики, статус человека.

Физическое состояние студенческой молодежи с каждым годом снижается, этот фактор определяется кризисом государственной системы, оборачивается снижением уровня здоровья студентов. Состояние здоровья студенческой молодежи является показателем здорового показателя нации. Поэтому мы преподаватели кафедры «Физическое воспитание» ТарГУ проявили интерес к взятой нами теме.

Задумывались ли вы когда-нибудь о влиянии спорта на судьбу студенческой молодежи нашей страны? Как спорт может повлиять на будущее государства? Все мы знаем, что нынешняя молодежь - наше общее будущее, будущее всего народа, страны. И от того, какими они вырастут, зависит дальнейшая судьба всего народа. И перед нами встает вопрос об их правильном воспитании. Как воспитать в них лидерские качества, уверенность в себе, чувство собственного достоинства? Как можно улучшить их успеваемость? Как уберечь их от пагубного влияния окружающей среды, сигарет, алкоголя, наркотиков? Спорт дает нам ответы на все эти вопросы.

Занятия физическими упражнениями и спортом имеют положительное влияние на человека, его личностные качества, особенно в раннем возрасте, когда его личность находится еще на стадии формирования и поддается влиянию. Физическая культура и спорт является универсальным решением всех проблем. В обычной жизни все мы склонны замечать только физическую пользу от спорта, в виде красивой фигуры, прямой осанки, при этом закрывая глаза на другие изменения. Но задумывались ли вы когда-нибудь, что спорт 
влияет на лидерские качества человека, его уверенность в себе, открытость, коммуникабельность? Занятия спортом в юношестве имеют значительное влияние на психологические черты человека. Это утверждение подтверждает нам следующие проведенные исследования.

Одним из приоритетных условий соблюдения ЗОЖ является оптимальный режим двигательной активности. Чтобы воспитать свободную личность, способную к активной творческой, профессиональной деятельностью и нравственному поведению, в республике происходит развитие и преобразование образовательной системы высших учебных заведений. Задачей кафедры «Физическое воспитание» в вузе является всестороннее развитие обучающихся, формирование интеллекта, нравственных качеств, забота о здоровье молодежи. Эти направления необходимо согласовывать с основными положениями реформы вузовской системы, на одном из первых мест стоит забота руководства организации образования о здоровье студента.

От каких факторов зависит здоровье человека? Доказано, что сохранение и укрепление здоровья человека находится в тесной взаимосвязи от оптимального режима двигательной активности. Физиологами подтверждено, что если условно уровень здоровья человека принять за 100\%, то из них 20\% это наследственные факторы, 20\% зависят от экологических условий (внешняя среда), 10\% - от работников медицины. Остальные 50\% зависят от того образа жизни, который ведет сам человек, его привычек.

При проведении нами социологического исследования (второй этап анкетирование) выявились следующие результаты:

1) Большинство опрошенных студентов гуманитарных специальностей не имеют вредных привычек. Ожидаемо, что процент юношей, имеющих вредные привычки, больше чем процент среди девушек.

2) На курсах спортивного совершенствования по видам спорта в ТарГУ у преподавателей кафедры физического воспитания занимаются более 411 студентов. Большая часть таких студентов занимается спортом со школьного возраста.

Календарь спортивных мероприятий в учебном году довольно насыщенный: соревнования вузовского значения, посвященные различным датам, республиканские, областные и городские мероприятия, в которых студенты ТарГУ принимают самое активное участие, становятся победителями и часто занимали призовые места.

В то же время большинство анкетируемых студентов проводит свободное время дома, общаясь в социальных сетях, в то время как опрошенные студентки проводят свободное время, общаясь с друзьями непосредственно. Однако не радует тот факт, что женская часть опрошенных студентов довольно пассивна, у них нет желания заниматься спортом. Это говорит о том, что предпочтения в проведении свободного времени у девушки и юноши имеют различия. Часть опрошенных студентов, как юношей, так и девушек, не выполняет утреннюю гимнастику, связывая это с нежеланием вставать пораньше.

Большинство респондентов уверены, что если бы у них была возможность начать новую жизнь, они непременно бы занимались спортом. 
3) Правильному питанию студенты, особенно проживающие в общежитии, не уделяют должного внимания. Многие студенты подрабатывают в вечернее и ночное время, чтобы помогать родителям в оплате за обучение, поэтому режим питания и труда и отдыха у них нарушен. Юноши и девушки сознают, что нужно тратить деньги на приобретение витаминов, полезные продукты питания и т.П., но есть некоторое количество студентов, которые могут тратить только небольшое количество средств.

4) Основная часть студентов считает, что здоровый образ жизни - это здорово. Некоторые считают, что для поднятия жизненного тонуса достаточно соблюдение режима дня, занятие физическими упражнениями и прогулки на природе. Радует, что большинство студентов и студенток вуза не курят по разным причинам. Совсем не курят студенты и студентки, занимающиеся спортом.

На вопрос «Абсолютно здоровая нация - это реальность или иллюзия?» большинство студентов считает, что это иллюзия.

\section{Выводы}

Необходимо, чтобы здоровый образ жизни играл важную роль в жизни студентов ТарГУ:

1. У студентов, активно занимающихся спортом в секциях вуза, города и области, систематически посещающих занятия по физической культуре формируется другое отношение к учёбе. Они знают что такое «режим дня», поэтому более собраны, организованы, внимательны, ответственны. Среди занимающихся спортом немало просто успевающий в учёбе и «отличников».

2. Двигательная активность является основным фактором оздоровления человека, она направлена на формирование защитных сил организма, на повышение общего уровня здоровья;

3. Для укрепления здоровья студентов ТарГУ, для повышения двигательной активности ввести преобразования в системе физического воспитания в вузе, которые увеличили бы показатели физического развития и подготовленности студентов.

\section{Литература}

1 Постановление Правительства Республики Казахстан от 23 августа 2012 года № 1080"; Постановление Примечание РЦПИ! 2-2), 2-3), предусмотренных подпунктами дополнения постановлением Правительства РК от 13.05.2016 № 292 (вводится в действие с 01.09.2017).

2 ГОСТ образования - высшего образования (утвержденный постановлением Правительства РК от 23,08.2012 г. № 1080)

Abstract. The paper considers the impact of physical education and sports on the students fitness and endurance for the educational process in the University youth.

Key words: health, healthy lifestyle (HLS), physical education, physical culture, student

Статья отправлена: 27.01.2020 г.

(С) Косырева И.И. 